\title{
Following the Leader: Examining Leadership Characteristics, Alcohol Use, and Hooking Up among College Students
}

\author{
Rose Marie Ward*, Judith L. Weiner \\ Miami University, Oxford, USA \\ Email: "wardrm1@muohio.edu \\ Received April $5^{\text {th }}$, 2012; revised May $18^{\text {th }}, 2012$; accepted June $10^{\text {th }}, 2012$
}

\begin{abstract}
Although it is generally assumed that leadership traits are linked to positive outcomes, it is unclear how they might be related to less desirable health behaviors. In a sample of 623 undergraduate students, a series of structural equation models examined the relationship between transformational leadership traits and risky health behaviors (i.e., alcohol consumption and hooking up). The models fit the data well and indicated that higher levels of transformational leadership traits were related to higher levels of alcohol consumption and risky sexual behaviors. It seems that those students who endorse higher transformational leadership characteristics are also embracing negative health behaviors.
\end{abstract}

Keywords: Alcohol; Hooking Up; College Students; Transformational Leadership

\section{Introduction}

Risky health behaviors are on the rise in college students. It is estimated that $40 \%-45 \%$ of college students are engaging in heavy episodic drinking each month with the proportion of college female drinking increasing more than college males (NCASA, 2007). Another risky health behavior that is increasing in prevalence is "hooking up" or sexual interactions with no expectations of a relationship (Bogle, 2008; Paul, McManus \& Hayes, 2000; Reiber \& Garcia, 2010). Moreover, risky alcohol consumption and sexual behaviors seem to co-exist (Goldstein, Barnett, Pedlow, \& Murphy, 2007; Testa \& Parks, 1996). As reported alcohol consumption increases, reported numbers of sexual experiences increases. In addition, both alcohol use and sexual experience have been linked to negative outcomes (e.g., sexual assault; Testa \& Dermen, 1999; academic outcomes; Bryant, Schulenberg, O’Malley, Bachman, \& Johnston, 2003). Another trend on college campuses is the implementation of "leadership institutes" or programs that seek to increase leadership characteristics among college students. These leadership institutes seem to be related to education and personal gains (Cress, Astin, Zimmerman-Oster, \& Burkhardt, 2001). However, it is unclear how leadership traits are related to social traits (e.g., alcohol consumption and sexual behavior) that are also increasing during the collegiate experience. The purpose of the current study is to determine if leadership characteristics are predictive of levels of risky health behaviors.

\section{Leadership and College Students}

Recently, the concept of leadership has been examined through the lens of transactional and transformational leadership styles. These leadership styles have been characterized by seven leadership factors (i.e., charisma, inspirational, intellectual stimulation, individualized consideration, contingent reward, management-by-exception, and laissez-faire; Bass, 1985). Through several extensive studies, this leadership model was

${ }^{*}$ Corresponding author. reduced to six factors combining the charismatic and inspirational components (Bass, 1988, 1990; Bass \& Avolio, 1994). As the concept of the leadership styles evolved, Avolio, Bass, and colleagues (Avolio, Bass, \& Jung, 1995; Bass \& Avolio, 1997) further expanded the measurement of the styles by developing the Multifactor Leadership Questionnaire (MLQ 5X) that supports a nine-factor model and quickly became the most widely used measure of leadership (Eagly, Johannesen-Schmidt, \& van Engen, 2003). Within this model, five factors were determined to assess transformational leadership (i.e., idealized influence attributes, idealized influence behaviors, inspirational motivation, intellectual stimulation, and individualized consideration; Avolio et al., 1999; Den Hartog, Van Muijen, \& Koopman, 1997).

Transformational leadership is considered to be an effective method that nurtures followers and inspires them to effectively contribute to the organization (Bass, 1990; Bass \& Bass, 2009). Bass (1990) explains that transformational leaders are goal oriented with the mission of the organization or group as a driving force. As previously mentioned, transformational leadership is comprised of five assets. The first asset is idealized influence attributes or qualities that instill pride in others through association with the leader. The second characteristic of transformational leadership is idealized influence behaviors or the ability to communicate the goals and mission of the organization. The next aspect is inspirational motivation or communicating optimism and excitement concerning the goals and future of the organization. Another aspect is intellectual stimulation or the ability to examine multiple viewpoint while solving problems. The final asset of transformational leadership is individualized consideration or providing attention and mentorship to followers (Avolio et al., 1999). Because transformational leadership relates to the success of organizations (Bass, 1990; Eagly et al., 2003), it will be the focus of the current investigation.

Furthermore, in research that compared males and females on leadership styles, females were more likely than males to be 
transformational leaders (Eagly, et al., 2003). In Eagly and colleagues' (2003) meta-analysis of leadership studies, women had statistically significantly higher scores on the measures of transformational leadership (as measured by the subscales of the MLQ 5X). However, the effect sizes across these studies were small according to Cohen's (1988) classifications of effect sizes. Whereas the meta-analysis was comprehensive in its focus, the analysis was on gender differences on the leadership styles and not specific to college students. It is unclear from the literature if the same pattern would exist for a collegiate sample.

There are programs aimed at developing leadership traits in college students. For example, LeaderShape

(http://www.leadershape.org/) is a leadership development program that seems to increase transformational leadership traits (Bass \& Bass, 2009). Additionally, several colleges have leadership institutes as part of their academic structure (e.g., Brown's Leadership Institute and the Leadership Institute at Harvard). Some programs target leaders or to increase leadership traits in attempt to combat a specific issue. Banyard and colleagues (2009) utilized student leaders in their sexual assault bystander programming (Banyard, Moynihan, \& Crossman, 2009) due to their influence on others. The general assumption across these programs are that leadership traits and skills are linked to positive outcomes; however, studies examining specific types of college student leaders provide evidence to the contrary for health outcomes.

Traditionally, students who are collegiate athletes and members of Greek social societies tend to be viewed as leaders on their respective college campuses. As such, researchers examine the differences of these students when compared to their collegiate peers. With respect to alcohol use, athletes and members of Greek organizations consume more alcohol than their peers. Specifically, leaders on athletic teams tend to drink more and experience more negative consequences than their teammates and other non-athletes (Leichliter, Meilman, Presley, \& Cashin, 1998). In addition, leaders in Greek societies drink more than members and non-members. Moreover, Greek leaders experience more alcohol-related consequences than other members (Cashin, Presley, \& Meilman, 1998). In general, leaders consume more alcohol than non-leaders (Spratt \& Turrentine, 2001). Furthermore, if it can be assumed that being an athlete is a sign of leadership, athletes drink more and have higher levels of risky sex compared to non-athletes (Grossbard, Lee, Neighbors, Hendershot, \& Larimer, 2007). However, there are no studies available that examine leadership traits level in relation to risky sexual behavior and alcohol consumption.

\section{Risky Health Behaviors and College Students}

Alcohol use is common on college campuses. Alcohol use rates on college campus have remained steady (NCASA, 2007) despite near universal movements on college campus to educate students about the effects of alcohol. For example, researchers estimate that over $40 \%$ of college students drink heavily (O'Malley \& Johnston, 2002). Not only are college students regular consumers of alcohol, they also experience the largest proportion of negative consequences associated with alcohol (e.g., black outs, injuries, academic issues, regretted sexual experiences, legal issues, sickness, hangover), and the number of negative consequences experienced by college students is increasing (NCASA, 2007). These consequences have costs to the student (e.g., grades, health, injury, and even death), the university (e.g., property destruction), and society. In addition, $50 \%$ of college male drinkers and $35 \%$ of female college drinkers report drinking and driving (NCASA, 2007). Approximately $24 \%$ of students report that they have missed class as result of drinking (Weschler, et al., 1998). College students report experiencing black outs or memory loss (52\% of heavy drinkers, Weschler et al., 1999), unprotected sex (17.1\%, Harford et al., 2002), and injuries (30\%, Jacobs, 2005) as a result of their alcohol consumption. Moreover, Abbey (2002) estimates that in $50 \%$ of sexual assault either the perpetrator or the victim or both are under the influence of alcohol. Furthermore, heavy drinking in college is related to higher rates of alcohol consumption and dependence 25 years after college (Sloan et al., 2011).

Alcohol consumption in college student differs across the genders. College women and men reported participating in frequent binge drinking $(20.9 \%$ and $25.2 \%$ of college students, respectively), frequently being drunk $(24.6 \%$ and $34.9 \%$, respectively), and drinking 10 or more drinks on a drinking occasion in the past 30 days $(16.8 \%$ and $29.2 \%$, respectively; NCASA, 2007). Whereas the participation rates currently differ, they might not for long. Women have experienced around a $30 \%$ increase in these behaviors since 1993 (NCASA, 2007).

Another high-risk behavior common to college students is hooking up. Hooking up or sexual behaviors outside the commitment of a relationship (Bogle, 2008; Paul \& Hayes, 2002) is fairly common on college campuses with $50 \%$ of students indicating that they hooked up in the last year (Owen, Rhoades, Stanley, \& Fincham, 2010). Researchers have argued that this recent trend towards hooking up reflects a shift in the dating paradigm (e.g., Bogle, 2008). Similar to risky alcohol consumption, hooking up is related to a number of negative outcomes (STI, unintended pregnancy; Grello et al., 2006; LaBrie, Earleywine, Schiffman, Pedersen, \& Marriot, 2005; Paul et al., 2000). In addition, hooking up is related to college student's alcohol consumption (Grello et al., 2006; Paul et al., 2000; Owen, Rhoades, Stanley, \& Fincham, 2010). Similar to trends in alcohol use, men more than women tend to hook up (Grello et al., 2003; Manning, Longmore, \& Giordano, 2005). In addition, in comparison to women, men are more likely to view the hook ups as positive (Owen \& Ficham, 2010).

Leadership traits are generally considered desirable and characteristics one might want to develop (as evidenced by the leadership institutes). In college students, however, leadership positions in athletics and Greek organizations have been linked to riskier alcohol consumption and sexual behaviors. It is unclear from the literature if leadership traits in general will also be related to levels of risky behaviors. Therefore, the purpose of the current project is to examine the relationship between leadership traits as measured by the MLQ $5 \mathrm{X}$ and risky behaviors (i.e., alcohol use and risky sex). In addition, a secondary purpose is to examine the role of gender with respect to leadership and risky behaviors.

\section{Methods}

\section{Participants}

Eleven small and medium-sized colleges and universities from the Midwest, Northwest, and Northeast United States participated. A total of 623 students completed the survey. The majority of the sample indicated that they were female $(55.9 \%$, 
$\mathrm{n}=348$; male: $30.3 \%, \mathrm{n}=189$; not selected: $13.8 \%, \mathrm{n}=86$ ). They had a mean age of $21.54(\mathrm{SD}=4.80)$, reported being Caucasian $(74.2 \%, \mathrm{n}=462)$, and were not married $(73.0 \%, \mathrm{n}=$ 455). A majority of the participants reported that their parents were well educated (Mother education - college or above, $49.28 \%, \mathrm{n}=307$; Father education-college or above, $54.74 \%$, $\mathrm{n}=341$ ). In addition, a variety of family incomes (from under $\$ 25 \mathrm{~K}$ to over $\$ 200 \mathrm{~K}$ ) and year in school (from first year student to graduate student) were represented (freshmen: $17.5 \%, \mathrm{n}=$ 109; sophomore: $13.5 \%, \mathrm{n}=84$; junior: $20.4 \%, \mathrm{n}=127$; senior: $17.8 \%, \mathrm{n}=111 ; 5^{\text {th }}$ year: $6.3 \%, \mathrm{n}=39$; graduate student: $9.8 \%$, $\mathrm{n}=61)$. Approximately $6.3 \%(\mathrm{n}=39)$ of the participants indicated that they participated in varsity sports. In addition, $18.5 \%$ $(\mathrm{n}=115)$ are members of Greek organizations and an addition $8.2 \%(\mathrm{n}=51)$ intend on pledging a Greek organization. Additionally, $20.4 \%(n=127)$ indicated that they were currently in a leadership position.

\section{Recruitment Procedure}

After receiving IRB approval from the first author's institution and each respective institution, potential participants were selected via a two-step method. During the first step, approximately 500 email addresses were randomly retrieved from each school's respective online directory. The second step included the online survey program testing the email address to determine if it was a working email address. Additional participants at one mid-sized Midwestern universities signed up for the study via an online recruitment tool, Sonasystems.com. Many of the students using Sonasystems.com received course credit in their Introduction to Psychology class for their participation.

\section{Online Survey Procedure}

The current project is part of a larger project on leadership, sexual health, and alcohol. Potential participants were sent an email invitation requesting their participation in the study. One reminder email was sent approximately one week following the initial contact to participants who did not complete the survey. The online survey was housed by Prezza Checkbox software at the principal investigator's host institution. All data collected were protected behind the institution's firewall and IP addresses were not pursued

\section{Measures}

Participants were asked basic demographic questions regarding age, gender, sexual orientation, marital status, parental marital status, and parental education levels.

Multifactor Leadership Question (MLQ-5X; Avolio, Bass, \& Jung, 1995). The 45-item inventory is a self- report measure that assesses transformational, transactional, and passive/ avoidant leadership characteristics. The MLQ-5X has nine scales - five of which measure transformational leadership. The Idealized Influence (Attributed) scale has four items and assesses the ability to garner respect through association (four items; e.g., "I instill pride in others for being associated with me."). The Idealized Influence (Behaviors) assesses the communication of values (four items; e.g., "I talk about my most important values and beliefs."). The Inspirational Motivation scale measures behaviors that exhibit excitement about future goals (four items; e.g., "I talk optimistically about the future.").
Intellectual Stimulation assesses problem-solving perspectives (four items; e.g., "I seek differing perspectives when solving problems."). The final scale for Transformative Leadership is Individualized Consideration or developing and mentoring followers (four items; "I spend time teaching and coaching."). Participants were instructed to report how frequently they engage in the behaviors and actions listed. Participants responded using a five-point Likert scale $(0=$ "Not at all" to $4=$ "Frequently, if not always"). Scales were averaged, and higher scores indicated that the participant endorsed more of each aspect of leadership. Previous research indicates good internal reliability and good test-retest reliability (Avolio \& Bass, 1995). For the current study, only the scales pertinent to transformational leadership were used; the five scales had .69, .72, .83,.77, and .66 internal consistencies, respectively. Means and standard deviations of the scales are in Table $\mathbf{1}$ as those used in national data collections of college-student drinking (e.g., NCASA, 2007). Participants were asked whether they ever consumed an alcoholic drink, the number of days in a typical week that they drink, the number of drinks they had on a typical drinking occasion, the highest number of drinks they had had on one occasion in the last 30 days, and the number of drinks, on average, they consumed for each day of the week. To facilitate their responses to these items, participants were provided with the definition of a standard drink (12 ounces of beer, 4 ounces of wine, or a 1-ounce shot of liquor; Wechsler, Lee, Kuo, Seibring, Nelson, \& Lee, 2002.

Risky Sex. Participants were asked three questions concerning their sexual experience. They were asked for the number of sexual experiences in the last week (sexual experiences were defined as any situation which was sexual in nature). In addition, participants were asked the number of hook ups they had in the last week. Consistent with the literature, a definition for hooking up was not provided. Finally, participants were asked to indicate the average number of people involved in the hook ups over the last week.

\section{Results}

\section{Descriptive Statistics}

Participants reported drinking an average of 1.75 days $(\mathrm{SD}=$ 1.46) with an average of 3.99 standard drinks $(\mathrm{SD}=3.10)$ per drinking occasion. On average, their highest drinking occasion in the last 30 days was 6.35 drinks $(\mathrm{SD}=5.21)$. Some participants reported drinking on every day of the week (Number of standard drinks-Monday: $\mathrm{M}=.08, \mathrm{SD}=.47$; Tuesday: $\mathrm{M}$

Table 1.

Descriptives of multifactor leadership questionnaire.

\begin{tabular}{lccc}
\hline \multicolumn{1}{c}{ Scale } & Mean & $\begin{array}{c}\text { Standard } \\
\text { Deviation }\end{array}$ & $\begin{array}{c}\text { Cronbach's } \\
\text { Alpha }\end{array}$ \\
\hline Idealized Influence Attributed & 2.52 & .68 & .69 \\
Idealized Influence Behavior & 2.61 & .69 & .72 \\
Inspirational/Motivational & 2.73 & .74 & .83 \\
Intellectual Stimulation & 2.63 & .69 & .77 \\
Individualized Consideration & 2.61 & .67 & .66 \\
\hline
\end{tabular}


$=.22, \mathrm{SD}=1.03$; Wednesday: $\mathrm{M}=.32, \mathrm{SD}=1.32$; Thursday: $\mathrm{M}=1.50, \mathrm{SD}=2.74$; Friday: $\mathrm{M}=3.25, \mathrm{SD}=3.57$; Saturday: $\mathrm{M}=3.55, \mathrm{SD}=3.61$; Sunday: $\mathrm{M}=.24, \mathrm{SD}=1.07$ ).

With respect to the risky sex variables, participants reported having an average of $1.41(\mathrm{SD}=2.91)$ sexual encounters. They reported hooking up an average of 1.27 times $(\mathrm{SD}=2.68)$ in the last week. In those hook up experiences, they reported having an average of .67 people $(\mathrm{SD}=.59)$.

\section{Gender Differences}

An oneway MANOVA examined gender differences across the five leadership scales. The overall model was significant, Wilk's Lambda $=.95, p=.01$, partial $\eta^{2}=.05$. The follow up oneway ANOVAs indicated significant gender differences for Idealized Influence Behavior, $\mathrm{F}(1,328)=6.98, p=.01$, and Inspirational Motivation, $\mathrm{F}(1,328)=4.94, p=.03$. See Table 2 for the means. Consistent with previous literature, an oneway MANOVA indicated significant gender differences across the alcohol consumption variables, Wilk's Lambda $=.85, p<.001$, partial $\eta^{2}=.12$. The follow up oneway ANOVAs indicated significant gender differences for typical number of drinks on a drinking occasion, $\mathrm{F}(1,401)=16.05, p<.001$, and peak drinking occasion, $\mathrm{F}(1,401)=30.21, p<.001$. However, in contrast to the literature, an oneway MANOVA examining gender differences in risky sex occurrences was non-significant, Wilk's Lambda $=.99, p=.83$, partial $\eta^{2}=.01$.

\section{Structural Equation Models}

The relationships between the constructs were assessed within a structural equation modeling framework using Mplus version 5.21. Models were proposed based upon theoretical predictions and examined using the following criteria: 1) theoretical salience; 2) global fit indices (chi-square goodness of fit, Comparative Fit Index: CFI \& Tucker-Lewis Index: TLI); 3) microfit indices (parameter estimates, Root Mean Squared Error of Approximation: RMSEA, and residuals); and 4) parsimony Each of the criteria was equally weighed in the selection of the final model. The criteria for theoretical fit maintain that the model must be predicted from documented theory and previous research. To evaluate the global fit indices, a non-significant chi-square indicates that the data does not significantly differ from the hypotheses represented by the model. Additionally for CFI and TLI, fit indices of above .90 (preferably above .95 ) will be the criteria utilized to indicate a well-fitting model (CFI: Hu \& Bentler, 1999; TLI: Hu \& Bentler, 1999). For RMSEA, a fit of less than .05 will be taken to indicate a well-fitting model (Browne \& Cudeck, 1992). Finally, the requirement of parsimony leads to the selection of a model with the fewest parameters that still meets the other criteria.

Two primary models were tested. The first model (see Figure 1) examined the transformational leadership characteristics and gender predicting alcohol use and risky sexual behaviors. The model fit the data well, $\chi^{2}(\mathrm{n}=543,49)=191.42$, CFI $=.97, \mathrm{TLI}=.96, \mathrm{RMSEA}=.07$. The second model (see Figure 2 for the parameter estimates) was similar to the first model except that gender was removed. The second model also fit the data well, $\chi^{2}(\mathrm{n}=543,41)=165.23$, CFI $=.98$, TLI $=.97$, RMSEA $=.08$. Since the second model is nested within the first model, a chi-square difference test examined the difference in the fit statistics, $\Delta \chi^{2}(8)=26.19, p=.0001$. The test suggests that the second model is a significant improvement over the first model.

\section{Discussion}

The characteristics of transformational leadership predict levels of alcohol consumption and hooking up in a collegiate sample. It seems that even when gender is accounted for the transformational leadership characteristics relate to higher levels of risky behaviors. This finding is consistent with studies that examined leaders on athletic teams (e.g., Leichliter et al., 1998) and in Greek organization (e.g., Cashin et al., 1998). It seems that regardless of the context of the leadership (i.e., athletic team, Greek organization, or in general) that transformational leadership traits are related to less positive health behaviors.

Table 2.

Means and standard deviations on variables by gender.

\begin{tabular}{lcc}
\hline & Male & Female \\
\hline Transformational Leadership & & \\
Idealized Influence (Attributed) & $2.49(.73)$ & $2.53(.65)$ \\
Idealized Influence (Behavior) & $2.48(.72)$ & $2.68(.67)$ \\
Inspirational & $2.63(.79)$ & $2.78(.70)$ \\
Intellectual Stimulation & $2.55(.74)$ & $2.66(.66)$ \\
Individualized Consideration & $2.49(.68)$ & $2.65(.65)$ \\
Alcohol & & \\
Number of Drinking Days per Week & $1.80(1.46)$ & $1.74(1.46)$ \\
Typical Number of Drinks & $4.88(4.10)$ & $3.56(2.39)$ \\
Peak Drinking Occasion in Past 30 Days & $8.40(6.74)$ & $5.39(3.96)$ \\
Risky Sex & & \\
Number of Sexual Encounters & $1.25(3.23)$ & $1.48(2.77)$ \\
Number of Hook Ups in Last Week & $1.55(3.80)$ & $1.15(2.12)$ \\
Number of Hook Up Partners & $.64(.58)$ & $.67(.60)$ \\
\hline
\end{tabular}




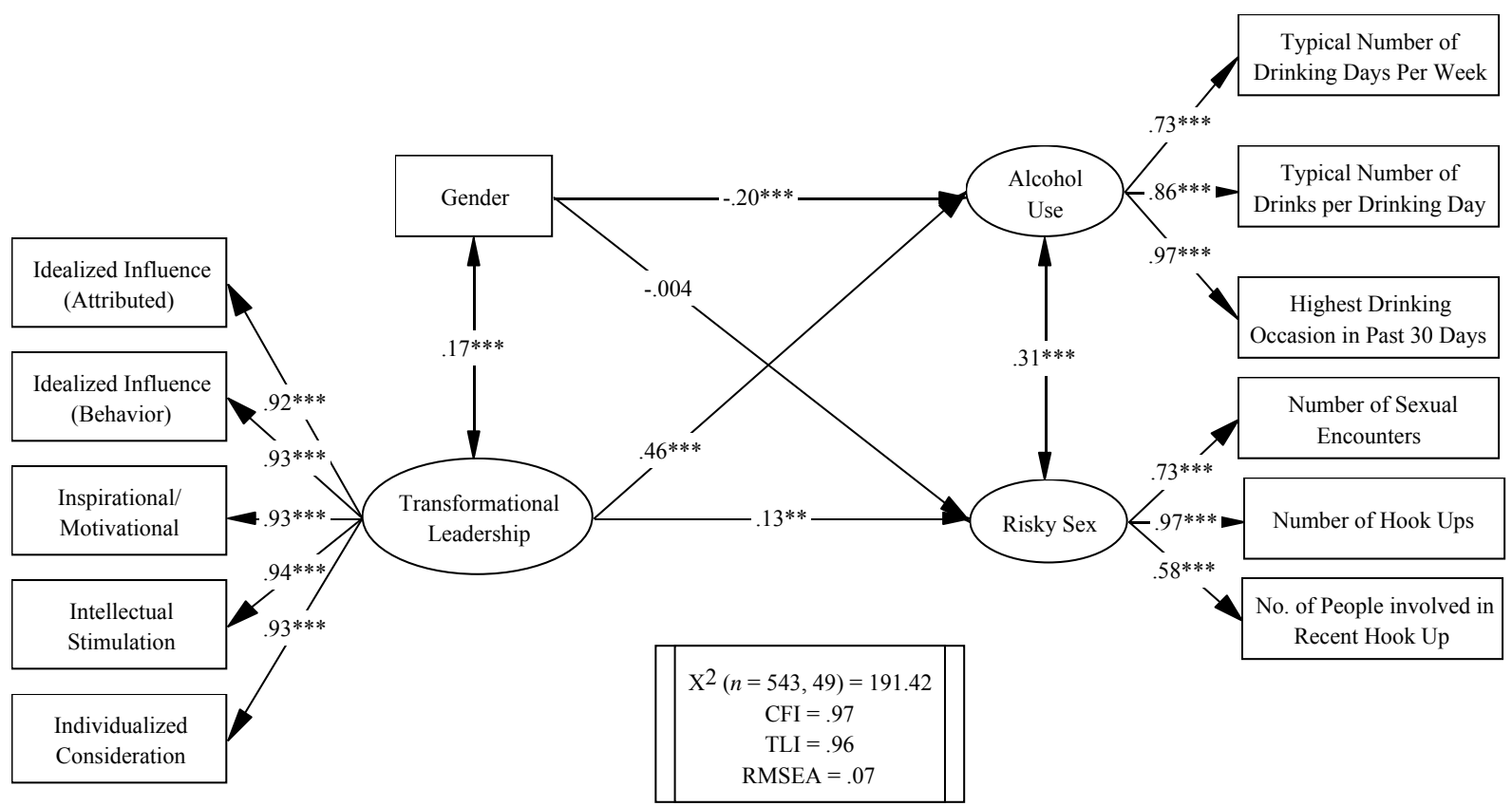

Figure 1.

Transformational leadership and gender predict risky sex and alcohol behaviors, ${ }^{*} p<.05 ;{ }^{* *} p<.01 ; * * * p<.001$.

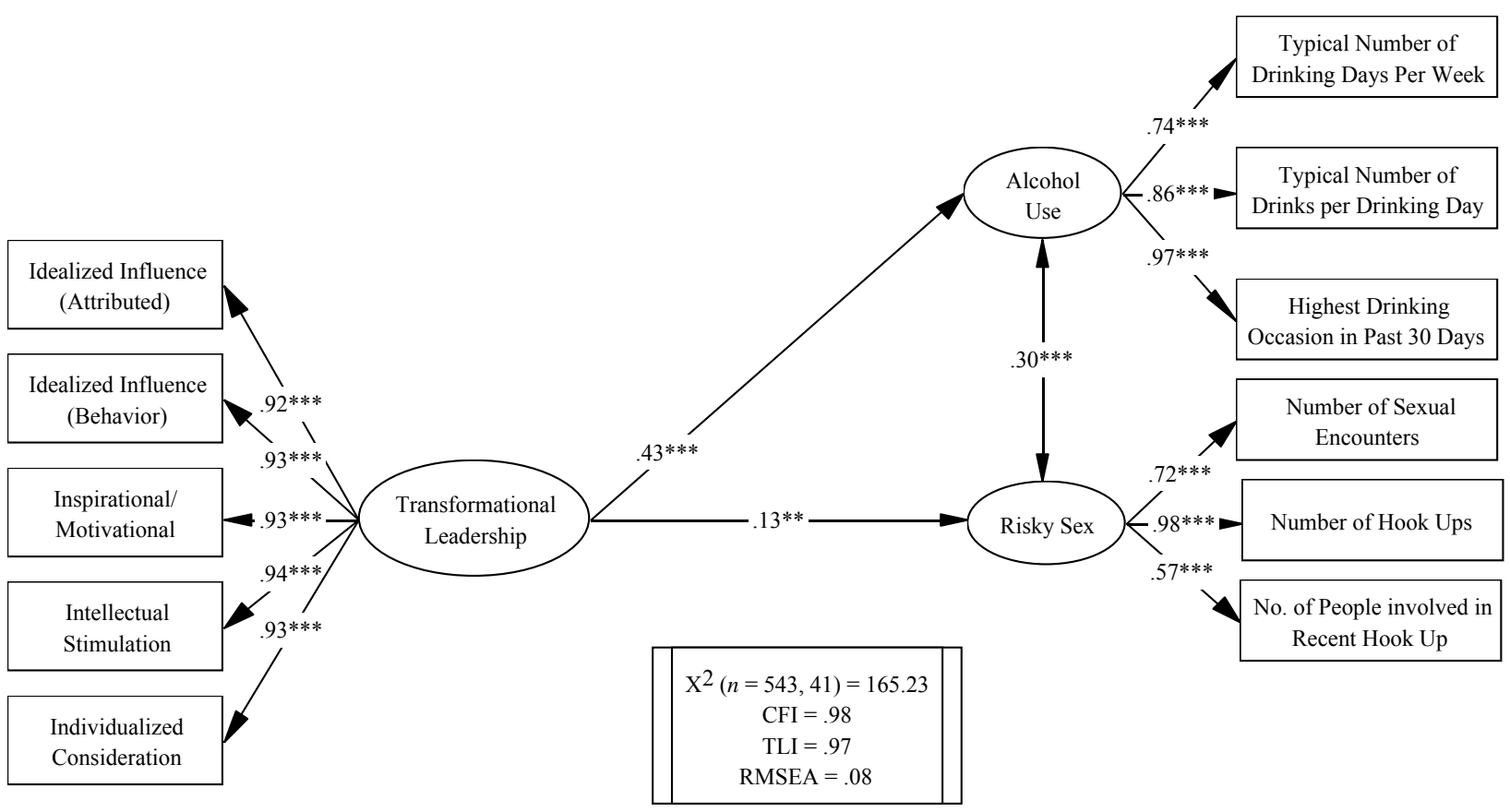

Figure 2.

Transformational leadership predicts alcohol use and risky sex, ${ }^{*} p<.05 ; * * p<.01 ; * * * p<.001$.

Interestingly, the multivariate analyses of the leadership characteristics and risky sexual behaviors did not replicate the previously literature completely (e.g., Eagly et al., 2003). With respect to the leadership characteristics, women reported higher levels of two of the subscales of transformational leadership. Further research is needed to determine if the lack of difference on the other aspects of transformational leadership is unique to the collegiate population. Moreover, there were no gender dif- ferences on the sexual experience items. This finding is surprising given the numerous studies to the contrary (e.g., Bogle, 2008; Owen et al., 2010; Paul \& Hayes, 2002). It is possible that the utilization of online survey methods might have lead to this result. Online surveys may be lead to only certain students electing to complete the survey and possibly less socially desirable responses (in contrast to Bogle's interviews).

Transformational leadership characteristics being linked to 
risky health behaviors has implications. Whereas these leadership characteristics are related to positive outcomes (e.g., successful organizations; Cress et al., 2001) and are considered traits desirable to promote, it is plausible that the promotion of these traits are also leading to increases in negative health behaviors as well. However, a longitudinal study is needed to test this relationship and establish a causal link. Potentially, the relationship between leadership traits and risky health behaviors could be the influence of a third variable (e.g., coping). Participants with leadership traits might use the risky behaviors to cope with the stress associated with their leadership characteristics.

Additional research is also needed to determine if the transformational leadership characteristics are related to the negative outcomes associated with risky behaviors. Whereas the current study links the characteristics to the risky behaviors and previous literature relates being an athletic leader or Greek organization leaders to more negative consequences (e.g., blacking out; Cashin et al., 1998), it is unclear is the leadership traits will relate to higher levels of consequences. Potentially, leadership characteristics might buffer the experiences of the negative consequences.

In the research, transformational leadership traits, alcohol consumption, and hooking up have differences across the genders. However, in the structural equation models, the influence of gender on these variables did not significantly improve the models. It is possible that the impact of the transformational leadership characteristics on the risky health behaviors is more predictive than gender. In addition, gender might moderate the relationship between the variables. The model should be examined separately across gender and utilizing tests of invariance. Given the relative dearth of literature in the risky health behavior and leadership area, additional research is needed.

This research is not without limitations. The data were collected via online questionnaires using email invitations. Unfortunately, the response rates for these invitations were low and potentially lead to a response bias. However, the levels of alcohol consumption (Weschler et al., 2002), leadership traits (Bass \& Avolio, 1997), and hooking up (Paul \& Hayes, 2002) are consistent with published values. In addition, the data were collected cross-sectionally. Further longitudinal research is needed to explore the direction and nature of the relationships. In addition, as mentioned previously potential third variables might be mediating the relationship between transformational leadership traits and risky health behaviors.

In college students, high levels of alcohol consumption and risky sexual behaviors are associated with a number of negative consequences (e.g., lower grades, accidentals, injuries, sexual assault, pregnancy, death; Abbey, 2002; Grello et al., 2006; Weschler et al., 1999). In contrast, leadership characteristics related to positive outcomes (Cress et al., 2001). However, in college students, it seems that these same characteristics are linked to higher levels of risky health behaviors. Given the recent movement to increase leadership characteristics in college students, it is important to examine the potential negative impact that an increase in these traits might have.

\section{REFERENCES}

Abbey, A. (2002). Alcohol-related sexual assault: A common problem among college students. Journal of Studies on Alcohol, 14, 118128.
Avolio, B. J., Bass, B. M., \& Jung, D. I. (1995). MLQ Multifactor leadership questionnaire: Technical report. Redwood City, CA: Mindgarden.

Avolio, B. J., Bass, B. M., \& Dong, J. (1999). Re-examining the components of transformational and transactional leadership using the Multifactor Leadership Questionnaire. Journal of Occupational and Organizational Psychology, 72, 441-462. doi:10.1348/096317999166789

Banyard, V. L., Moynihan, M. M., \& Crossman, M. T. (2009). Reducing sexual violence on campus: The role of student leaders as empowered bystanders. Journal of College Student Development, 50, 447-457.

Bass, B. M. (1985). Leadership and performance beyond expectations. New York: Free Press.

Bass, B. M. (1988). The inspirational process of leadership. Journal of Management Development, 7, 21-31. doi:10.1108/eb051688

Bass, B. M. (1990). Bass and Stogdill's handbook of leadership. New York: Free Press.

Bass, B. M., \& Avolio, B. J. (1994). Improving organizational effectiveness through transformational leadership. Thousand Oaks, CA: Sage Publications.

Bass, B. M., \& Avolio, B. J. (1997). Full range leadership development: Manual for the Multifactor Leadership Questionnaire. Palo Alto, CA: Mindgarden.

Bass, B. M., \& Bass, R. (2009). The bass handbook on leadership. New York: Free Press.

Bogle, K. A. (2008). Hooking up: Sex, dating, and relationships on campus. New York: New York University Press.

Bryant, A. L., Schulenberg, J. E., O’Malley, P. M., Bachman, J. G., \& Johnston, L. D. (2003). How academic achievement, attitudes, and behaviors relate to the course of substance use during Adolescence: A 6-year, multiwave national longitudinal study. Journal of Research on adolescence, 13, 361-397. doi:10.1111/1532-7795.1303005

Cashin, J. R., Presley, C.A., \& Meilman, P.W. (1998). Alcohol use in the Greek system: Follow the leader? Journal of Studies on Alcohol, 59, 63-70.

Cohen, J. (1988). Statistical power analysis. NewYork: Routledge Academic.

Cress, C. M., Astin, H. S., Zimmerman-Oster, K., \& Burkhardt, J. C. (2001). Developmental outcomes of college students' involvement in leadership activities. Journal of College Student Development, 42, $15-27$.

Den Hartog, D. N., Van Muigen, J. J., \& Koopman, P. L. (1997). Transactional versus transformational leadership: An analysis of the MLQ. Journal of Occupational and Organizational Psychology, 70, 19-34. doi:10.1111/j.2044-8325.1997.tb00628.x

Eagly, A. H., Johannesen-Schmidt, M. C., \& van Engen, M. L. (2003). Transformational, transactional, and laissez-faire leadership styles: A meta-analysis comparing women and men. Psychological Bulletin, 129, 569-591. doi:10.1037/0033-2909.129.4.569

Goldstein, A. L., Barnett, N. P, Pedlow, C. T., \& Murphy, J. G. (2007). Drinking in conjunction with sexual experiences among at-risk college student drinkers. Journal of Studies on Alcohol and Drugs, 68, 697-705.

Grello, C.M., Welsh, D.P., Harper, M.S. \& Dickson, J.W. (2003). Dating and sexual relationship trajectories and adolescent functioning. Adolescent and Family Health, 3, 103-112.

Grello, C.M., Welsh, D.P. \& Harper, M.S. (2006). No strings attached: The nature of casual sex in college students. The Journal of Sex Research, 43, 255-267. doi:10.1080/00224490609552324

Grossbard, J. R., Labrie, J. W., Hummer, J. F., Pedersen, E., \& Neighbors, C. (2009). Is substance use a team sport? Team attitudes, perceived norms, and alcohol and marijuana use among male and female intercollegiate athletes. Journal of Applied Sport Psychology, 21, 247-261. doi:10.1080/10413200903019145

Harford, T. C., Wechsler, H., \& Seibring, M. (2002). Attendance and alcohol use at parties and bars in college: A national survey of current drinkers. Journal of Studies on Alcohol, 63, 726-733.

$\mathrm{Hu} \&$ Bentler (1999). Cutoff criteria for fit indexes in covariance structure analysis: Conventional criteria versus new alternatives, Structural Equation Modeling, 6, 1-55. 


\section{R. M. WARD, J. L. WEINER}

doi:10.1080/10705519909540118

Leichliter, J. S., Meilman, P. W., Presley, C. A., \& Cashin, J. R. (1998). Alcohol use and related consequences among students with varying levels of involvement in college athletes. Journal of American College Health, 46, 257-262. doi:10.1080/07448489809596001

National Center on Addiction and Substance Abuse. (2007). Wasting the best and the brightest: Substance abuse at America's colleges and universities. New York, NY: Author.

O’Malley, P. M., \& Johnson, L. D. (2002). Epidemiology of alcohol and other drug use among American college students. Journal of Studies on Alcohol [Supplement], 14, 23-29.

Owen, J. J. \& Fincham, F. D. (2010). Young adults' emotional reactions after hook up encounters. Archives of Sexual Behavior, 40, 321330.doi:10.1007/s10508-010-9652-x

Owen, J. J., Rhoades, G. K., Stanley, S. M., \& Fincham, F. D. (2010). "Hooking up" among college students: Demographic and psychosocial correlates. Archives of Sexual Behavior, 39, 653-663. doi:10.1007/s10508-008-9414-1

Paul, E.L., \& Hayes, K.A. (2002). The casualties of "casual" sex: A qualitative exploration of the phenomenology of college students' hookups. Journal of Social and Personal Relationships, 19, 639-661. doi: $10.1177 / 0265407502195006$

Paul, E. L., McManus, B., \& Hayes, A. (2000). "Hookups": Characteristics and correlates of college students' spontaneous and anonymous sexual experiences. Journal of Sex Research, 37, 76-88.

doi:10.1080/00224490009552023

Reiber, C., \& Garcia, J. R. (2010). Hooking up: Gender differences, evolution, and pluralistic ignorance. Evolutionary Psychology, 8,
390-404.

Sloan, F., Grossman, D., \& Platt, A. (2011). Heavy episodic drinking in early adulthood and outcomes in midlife. Journal of Studies on Alcohol and Drugs, 72, 459-470.

Spratt, J. T., \& Turrentine, C. G. (2001). The leader factor: Student leadership as a risk factor for alcohol abuse. Journal of College Student Development, 42, 59-67.

Testa, M., \& Dermen, K. H. (1999). The differential correlates of sexual coercion and rape. Journal of Interpersonal Violence, 14, 548561. doi: $10.1177 / 088626099014005006$

Testa, M., \& Parks, K. A. (1996). The role of women's alcohol consumption in sexual victimization. Aggression and Violent Behavior, 1, 217-234. doi:10.1016/1359-1789(95)00017-8

Wechsler, H., Dowdall, G.W., Maenner, G., Gledhill-Hoyt, J., \& Lee, H. (1998). Changes in binge drinking and related problems among American college students between 1993 and 1997. Journal of American College Health, 47, 57-68. doi:10.1080/07448489809595621

Wechsler, H., Lee, J. E., Kuo, M., Seibring, M., Nelson, T. F., \& Lee, H. (2002). Trends in college binge drinking during a period of increased prevention efforts: Finding from 4 Harvard School of Public Health College Alcohol Study surveys: 1993-2001. Journal of American College Health, 50, 203-217.

doi:10.1080/07448480209595713

Wechsler, H., Molnar, B. E., Davenport, A., \& Baer, J. (1999). College alcohol use: A full or empty glass? Journal of American College Health, 47, 247-252. doi:10.1080/07448489909595655 